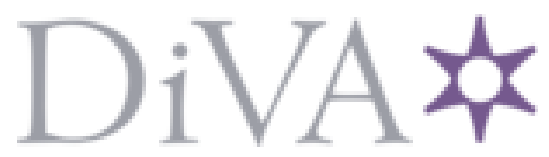

http://www.diva-portal.org

\title{
Postprint
}

This is the accepted version of a paper published in Journal of Cleaner Production. This paper has been peer-reviewed but does not include the final publisher proof-corrections or journal pagination.

Citation for the original published paper (version of record):

Bertoni, A., Bertoni, M., Isaksson, O. (2013)

Value visualization in Product Service Systems preliminary design.

Journal of Cleaner Production, 53: 103-117

http://dx.doi.org/10.1016/j.jclepro.2013.04.012

Access to the published version may require subscription.

N.B. When citing this work, cite the original published paper.

Permanent link to this version:

http://urn.kb.se/resolve?urn=urn:nbn:se:bth-6796 


\section{Value Visualization in Product Service Systems Preliminary Design}

Alessandro Bertoni (Corresponding author)

Division of Innovation and Design, Luleå University of Technology, Luleå, Sweden.

Luleå University of Technology, 97187, Luleå, Sweden Tel: 46 (0)920 492371. mail: alessandro.bertoni@1tu.se.

Marco Bertoni

Division of Innovation and Design, Luleå University of Technology, Luleå, Sweden.

Luleå University of Technology, 97187, Luleå, Sweden. Tel: +46 (0)920 492583, mail: marco.bertoni@1tu.se.

Ola Isaksson

GKN Aerospace Engine Systems Sweden, Trollhättan, Sweden.

Product Development, SE-461 81 Trollhättan, Sweden. Tel: +46 (0)520 292335, mail: ola.isaksson@gknaerospace.com.

Keywords: preliminary design, product-service systems, color coding, value visualization, decision making. 


\section{Value Visualization in Product Service Systems Preliminary Design}

Emerging from a study in the European aerospace industry, this paper identifies a gap in the way value-related information is communicated to designers of hardware in the preliminary stages of Product Service System (PSS) design. To fit this gap a Lifecycle Value Representation Approach, named LiVReA, that uses color-coded 3D CAD models to enable value information to be translated into visual features, is presented. Such approach aims at enhancing designers' awareness of the value contribution of an early design concept on the overall PSS offer by complementing requirements-based information with criteria reflecting the fulfillment of customers and system value. The paper details the development of the approach, its underlying rationale, the results of preliminary validation activities and the potential for industrial application in the light of the currently available PSS representation tools.

Keywords: preliminary design, product service systems, color coding, value visualization, decision making, lifecycle value.

\section{$1 \quad$ Introduction}

Design decisions are associated with consequences (Andreasen and Olesen, 1990; Duffy and Andreasen, 1993), which can either be intended or unintended, and either good or problematic (Borg et al., 2000). When designing a product or service, such consequences become evident only later in the process, when the architecture of the solution has already been defined, capital has been committed, and it is costly and timeconsuming to make changes.

Product Service Systems or PSS (Manzini et al., 2001; Mont, 2002; Tukker, 2004; Baines et al. 2007) exacerbate this design process "paradox", a phenomenon described by Ullman (2003). PSS design urges for an early integration of hardware software and services to gain competitive advantage in the market. This raises the level of system 
complexity, reduces costs and usage predictability, and asks for additional knowledge about the later stages of the product lifecycle (Meier et al. 2010).

Such complexity causes traditional Systems Engineering (SE) and Concurrent Engineering (CE) approaches to be weak in conveying information in preliminary PSS design (Molloy et al. 2009). Instead of focusing on requirements and cost analysis, PSS solutions should rather be developed with customer value in focus (Shimomura et al., 2009; Meier et al. 2010), and design decisions should be based on the value contribution that a solution is expected to generate along the system lifecycle (Isaksson et al. 2009).

The ability to communicate value is crucial to stimulate the discussion about which needs to prioritize, which lifecycle aspects to improve, which engineering characteristics to prefer, and, eventually, to grow a common understanding of the lifecycle consequences at system level of an early design decision.

In PSS design, the lack of means for displaying value causes designers either to select solutions that ensure optimal technical performances without considering lifecycle matters appropriately, or to base critical design choices on gut-feelings and intuition (Ericson et al., 2007).

This research has identified a gap in the way value-related information is communicated to designers when dealing with the design of a hardware associated to a PSS. In spite of a plethora of techniques available for PSS representation, only a few are found suitable to indicate which physical product concepts optimise value provision along the system lifecycle. The aim of this paper is, therefore, to describe an approach, named Lifecycle Value Representation Approach (LiVReA), which uses color-coded 3D CAD models to display the value contribution of hardware within a PSS offer.

The approach has emerged from the findings of a study conducted in the aerospace manufacturing industry, which relate to the engineering need for visualizing value 
information during sub-system design, and to methods and tools for implementing visualization capabilities. The approach has been verified by means of ethnographic observations on university students in engineering design: protocol analysis was applied to compare the behavior of eight design teams working on an identical design task using two alternative visualization methods.

After this introduction Section 2 presents the context in which the work was conducted and the research methodology. Section 3 describes the standpoint from which the value visualisation approach has been developed, reviewing the notion of value for PSS design as emerged from the available literature. Section 4 deepens the literature review in the topic of PSS representation highlighting gaps and trends for value visualization. Section 5 describes the findings from the empirical investigation with regards to the engineering need for visualizing value-related information in PSS. It also illustrates the approach used to translate the results of the value assessment into colorcoded representations, exemplifying it using an aero-engine component. Section 6 describes how verification activities were conducted, which is the method chosen (protocol analysis), the coding scheme and the experiment setup. Section 7 presents the results of these activities, while Section 8 discusses their relevance for the development of a decision support tool for PSS design. Section 9 draws the final conclusions.

\section{Research methodology and research context}

The research context has been provided by the analysis of real industrial problems within a European Commission's Seventh Framework Programme (FP7) project named CRESCENDO (Collaborative and Robust Engineering using Simulation Capability Enabling Next Design Optimisation - http://www.crescendo-fp7.eu/) between May 2009 and October 2012. 
The research can be methodologically likened to action research. According to Avison et al (1999, p. 94), action research is a qualitative research methodology "particular in the way it associates research and practice, so research informs practice and practice informs research synergistically". It implies the direct participation of researchers and practitioners in the research process and can be used to increase the understanding of how a change in one's action or practice can positively impact the “community of practice" (McNiff, 2002; Wenger, 1998). Action research was chosen because proven to be beneficial for understanding ill-structured problems of complex organizations (Avison et al., 1999).

The definition and the clarification of the problem domain have been conducted mainly through the authors' active participation in physical work-meetings within the project. Six multi-day physical workshops have been held with major European companies with experience in aircraft and engine development programmes, involving 12 different partners (i.e., aircrafts manufacturers, aero-engine component manufacturers, universities, research centers and software vendors). The problem has further been detailed in collaboration with a major Swedish aircraft sub-system manufacturer. Data have been collected during several multi-day company visits at the industrial partner's facilities. Semi-structured interviews and focus groups have been used as main data collection methods. The data gathering activity has involved managers, engineers and IT experts with knowledge on product and service development processes.

Reflective learning has been aided by the continuous participation in regular debriefing activities, which have taken the form of weekly virtual meetings with design experts, who have participated with their knowledge and expertise to the development of a preliminary mock-up for value visualization. 
The approach has initially been validated in review meetings with the industrial project partners. In parallel, the authors have conducted ethnographic observations during design sessions conducted in a laboratory environment. The data from the observations have been coded and analyzed using protocol analysis (Gero and Mc Neill, 1998), to study the behaviors and observe the temporal aspects of the design episodes (Mc Neill et al., 1998). Protocol analysis has its roots in the "think aloud" method (Ericsson and Simon, 1993) (van Someren et al., 1994), where designers are literally asked to think aloud, so to record the verbalization for later analysis. The coding dimensions have been defined from what proposed by Gero and Mc Neill (1998) and later used by Sakao et al. (2011) for the analysis of a PSS design process.

\section{Using value as a driver for PSS design}

Literature reports three major ways to develop a new methodology for PSS development (Wang et al., 2011). A first stream aims for an inclusion of service operations into product development to provide product-service solutions (see: Aurich et al. 2006). A second stream focuses on the development and management of physical products to provide a modified product, which is easy to be serviced (see: Sundin et al. 2009). A third stream focuses on the improvement of methods and tools from other sciences in order to develop PSS (see: Morelli, 2006; Maussang et al. 2009).

The second stream emerges from what observed by Sundin et al. (2009) in the Swedish manufacturing industry, where companies use standard products and do not adapt the hardware to the product/service systems provision. Cavalieri and Pezzotta (2012) in their recent review of PSS engineering confirm that manufacturers still adopt approaches based on a traditional engineering perspective to design and develop their integrated solutions. This is explained by the fact that many products are still sold 
traditionally to the customer, as well as by the persistence of a technocratic culture that overlooks the need of a methodological and systematically engineering of the intangible elements.

Nevertheless, as the volumes sold through PSS increase, products need to adapted to PSS (Sundin et al., 2009), because service processes are subjected to the characteristics of the hardware (Becker et al. 2010). For instance, consulting and maintenance processes differ on the base of size, configuration or longevity of a physical good or component. Hence, with product design wisely oriented toward PSS, obstacles can be reduced and profits increased.

The decision about which hardware development strategy to pursue is based on its assumed value. Engineers might plan for longer service intervals, choosing technologically advanced components and materials ensuring the product to last throughout a normal lifecycle (Sundin et al., 2009); or they might prefer to reduce the costs for the physical product, planning for shorter service intervals and more frequent interventions for spare parts replacement.

Elaborating from what proposed by Sundin et al. (2009), the authors define "value" of a PSS hardware as the level to which a product, or a technical solution fulfills the PSS stakeholders' needs along its lifecycle. This definition aims to cope with the problem of understanding the impact on the overall value of the PSS offer of a technical change at sub-system/component level. Five main stakeholders are identified as relevant in such a perspective: the end users, the customers (mainly in a business-to-business context), the company, the institutions and the environment. The objective of the value assessment process becomes, therefore, to provide a measurable approximation of the "value contribution" of the hardware for these stakeholders. This measurement becomes first the "object" around which the discussion on solution strategies for the PSS offer 
revolves, and second the point around which the design team members find an agreement on the early product specifications.

\subsection{The meaning of value in PSS design}

As suggested by the PSS literature, value has to be found at the intersection of tangible and intangible dimensions (Brandstötter et al. 2003, Tukker and Tischner 2006, Wang et al., 2011, Cavalieri and Pezzotta 2012). Kowalkowski and Kindström (2009) are among the firsts to propose a structured, 3-layered hierarchy of value criteria for PSS design. They distinguish between Product-based, Service-based and Relationship-based values. Product-based values include "traditional" product performances, quality and unit price. They are also related to environmental impact and sustainability (Goedkoop et al., 1999), because awareness of sustainability issues is critical to plan for products that maximize the expected life cycle value. Service-based values include operational costs, customization benefits and service consistency, while Relationship-based values include proactivity, trust, long-term commitment and shared norms and mind-sets. The latter are based on the idea that the supplier and the customer maintain a relationship over time (Grönroos, 1996).

The need to objectify value, translating the need description into meaningful information for hardware engineers, has suggested the authors to look at the Systems Engineering (SE) literature, where handful value-oriented methodologies have been proposed to support the early phases of complex systems design.

PSS are "complex systems" too (Baines et al., 2007, Isaksson et al., 2009, Vasantha et al., 2012): their purpose is wider and the relationships among actors more sophisticated than in traditional product or service development. Hence, methodologies such as Value-Driven Design (VDD) (Collopy and Hollingsworth, 2011) and 
TradeSpace exploration (Ross et al., 2004) have been found applicable to detail the PSS value hierarchy into criteria supporting value assessment studies.

A VDD value function (Collopy and Hollingsworth, 2011) takes as input a set of "extensive attributes" for the system - such as performance, reliability, maintainability, safety, cost, and technical risk attributes, to produce a single scalar for each design (called Surplus Value), which is essentially a surrogate object for profitability. Extensive Attributes (Collopy and Hollingsworth, 2011) recall Product-based values (Kowalkowski and Kindström 2009), although they do not explicitly contain sustainability aspects.

In System Engineering, with systems characterized by high cost, long lifecycles, high complexity, interdependencies with other systems and dynamic operational contexts, value is also determined by the capability to maintain or improve the system functions in the presence of changes. TradeSpace exploration (Ross et al., 2004) considers customer value embedded in the customer process context, and utilizes "ilities" to evaluate the system robustness under changing process conditions. Ilities, which include criteria such as survivability, adaptability, flexibility, scalability, versatility, modifiability and robustness, get close to the notion of Service-based values (Kowalkowski and Kindström 2009). Similarly, Service-based values echo the Real Option for Flexibility concept proposed by Saleh et al. (2003).

Relationship-based values get close to the notion of Intangibles proposed by Steiner and Harmor (2009). Their framework arrays goods and services on a continuum of relative tangibility - with goods being more tangible and services more intangible - and propose an Intangible value layer associated with knowledge, emotion and experience. 
Building from the parallelism between the PSS value hierarchy and the value-related SE literature, the authors have cascaded down two families of criteria to be used for the value assessment of products and technologies in a PSS offer. These families have been defined as "Value Dimensions" and "Value Drivers" (Figure 1).

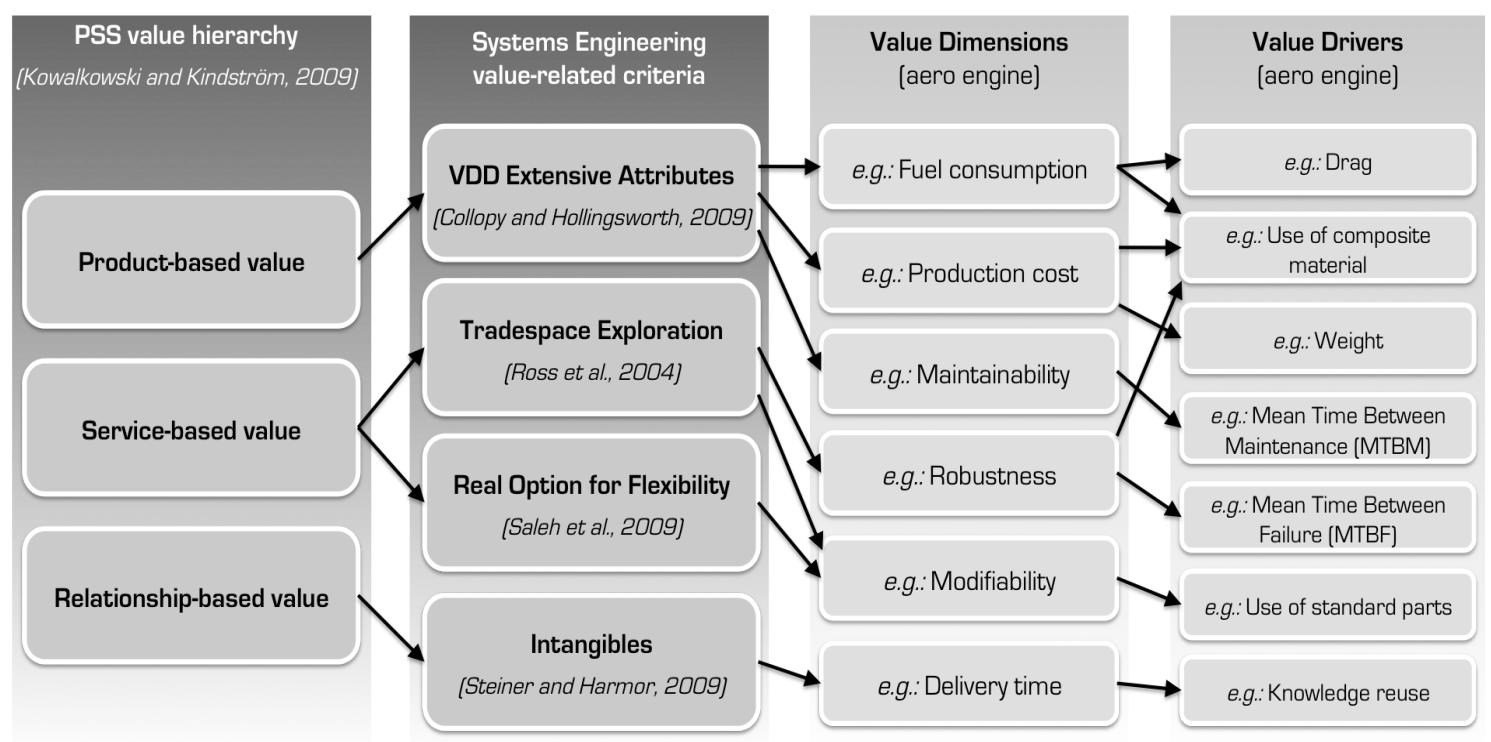

Figure 1: PSS value criteria (Kowalkowski and Kindström, 2009) vs. Criteria for value analysis of complex systems.

Value Dimensions are directly derived from the attributes used in the VDD literature, and from the other SE concepts reviewed in this section. Value Dimensions originate from the needs description and represent directions of investigation that are suggested to have an influence on the value contribution of the hardware being designed. Examples of Value Dimensions for a complex product, such for instance an aircraft engine, are: Fuel consumption, Robustness or Comfort.

Value Drivers express key engineering characteristics of the component/technology that are believed to influence the value perceived by all the stakeholders (i.e. end user, customer, company, society and environment). Value Dimensions and Value Drivers feature a n:n relationship: A Dimension can be cascaded down to many Drivers, and a Driver can relate to more than one Dimension. Examples of Value Drivers for an 
aircraft engine are: Weight, Use of composite material, or Mean Time Between Maintenance (MTBM).

The framework presented in Figure 1, which shows the links between the PSS value hierarchy, the value criteria for the analysis of complex system, Value Dimensions and Value Drivers, constitutes the reference framework upon which the authors have developed the PSS value visualization approach.

\section{$4 \quad$ Towards PSS value visualization}

Understanding the value contribution of a PSS challenges manufacturing companies and their customers to compose the development team in a new way, emphasizing cross disciplinarity (Isaksson et al. 2009).

A number of disciplines are needed to master the complexity of the value assessment activities: engineers have to collaborate with individuals that have knowledge on the different lifecycle aspects of the system, in order to populate a value model. This, however, emphasizes the risk of significant crossover and conflict between engineering, systems architects and business development. For this reasons, the authors consider visualization capabilities crucial to enhance the communication among these actors about the multifaceted factors and interactions which determine the value of a PSS along its lifecycle, and that influence the design decision-making process.

This section reviews how PSS concepts and processes are represented nowadays in literature and practice, and spotlights the role of information visualization tools for value communication.

\subsection{Representing PSS: major approaches}

The visual representation of information plays an important role in design: By illustrating a problem it helps humans in building and using their mental model when 
searching for solutions (Simon, 1996). Also, it fosters communication by achieving situation awareness so to derive knowledge for actions (Endsley, 1995; Klein, 1989). Several authors (Sakao and Shimomura 2007, Vasantha et al. 2011) stress the importance of PSS representations in the design process. By illustrating the actual concept and communicating the relationship between PSS elements (Geum and Park, 2011), these representations increase people's comprehension of a complex yet invisible system, nurturing dialogue and facilitating the achievement of a joint understanding of the offer (Lim et al. 2012).

Lim et al. (2012) classify existing tools for PSS representation into three categories according to their focus:

- relational networks of PSS stakeholders, showing the relationship of such stakeholders and the aspects involved in the relationship.

- processes of companies and customers providing and experiencing PSS respectively, which depict a series of information related to the PSS provision in chronological order.

- others, focusing on the role of technology in product service integration or on the hierarchy of PSS elements.

Systems Maps (van Halen et al., 2005) and Interaction Maps (Morelli, 2006) are among the most discussed tools in the first category. They capture material, information, and financial flows among PSS stakeholders, together with more indirect relationships and/or dependences between them. Other approaches include Service Triangle Models (Kim and Lee, 2009), which display triangular relationships between stakeholders and resources (tangible or intangible), and Relation-based Models (Kang et al., 2011), which visualize the interdependent relationships between product, service, and stakeholders. 
PSS process representation are instead mostly based on the Service Blueprint (Shostack, 1981), which displays service activities as flowcharts with interactions among providers and customers, including employee actions in onstage (visible to customers), backstage (invisible), and support process (see: Boughnim and Yannou, 2005; Morelli, 2006).

Over the years, a number of extended versions of Service Blueprint have been proposed to better capture all the relevant aspects of PSS design:

- the Extended Service Blueprint (Shimomura et al., 2009) introduces the use of Business Process Modeling Notation (BPMN) for PSS representation;

- the Modified Service Blueprint (Lee and Kim, 2010) highlights providercustomer interactions;

- the Conceptual Service Blueprint (Geng and Chu, 2011) highlights the roles of service staff and product system to support the customer;

- the Product Service Blueprint (Geum and Park, 2011) recognizes the importance of investigating the flow of product use in PSS design;

The third category includes Offering Diagram (van Halen et al., 2005), Functional Block Diagram (Maussang et al., 2009), Technology Road Mapping (Geum et al., 2011), the PSS Layer Method (Müller et al., 2009) and the PSS Board (Lim et al. 2012).

\subsection{PSS value visualization}

Methods and tools for PSS representation put a strong emphasis on stakeholders and processes. Also, they stresses the role of software and services in the description of what a PSS is, often neglecting the role of the hardware with regards to value provision. Kowalkowski and Kindström (2009) are among the firsts to recognize the need to expand PSS representation beyond traditional techniques to visualize value-related 
information. They explicitly discuss how the value of a PSS is visualized in industry along the different phases of the lifecycle, highlighting purposes, techniques, stakeholders and best practices. Case studies, business cases, reference sites and promotion of successful examples are recognized as the most used strategies in the development stage. These methods are mainly directed toward internal stakeholders and external customers by "integrating various forms of evidence in order to create a total impression" (Kindström et al., 2012 p. 8), they are suitable when the main purpose of the visualization is the promotion of the PSS processes and mindset. Yet, cases and examples emphasize business aspects rather than technical enablers, therefore they are not straightforwardly applicable to the problem of displaying how a hardware contributes to a given performance (thus to any Value Dimensions or Value Driver).

Kim et al. (2009) propose a different approach, which uses graphs to map the relationship between stakeholders' activities and value, creating an ontological representation of value and PSS. The lack of any clear indication about how a product should be redesigned when aiming for value maximization represents a main limitation of the approach when applied for the design of a product or technology.

\subsection{Using CAD for PSS value visualization}

In general, PSS representation techniques are found weak in conveying all necessary entities to inform PSS design decisions. Some authors (Ma et al. 2002), for instance, complain that flowcharts and diagrams are unable to capture all the aspects through which customers evaluate a combination of product and services. Others (Maussang et al., 2009; Vasantha et al. 2012) highlight that they need to be extended and deepened to support the evaluation of alternative PSS solution instances.

The adoption of multiple visualization strategies is regarded as central by the companies to succeed (Kindström et al. 2012) in PSS design. In this perspective, recent 
literature shows an increasing interest towards using CAD tools for the integrated representation of functions, service activities, and product behaviors (Hara et al., 2009). In spite of the shortcomings in conveying usage, manufacturing and lifecycle information reported in literature (Hannah et al. 2012), the recent market trends show that the scope of CAD/PLM is extending to support the analysis of a wider range of data. Recent releases embed modules and functions aiming at capturing customer needs and technical requirements, defining systems architecture, modeling and validating systems behavior, and managing embedded software.

CAD models are popular not only because they are easily shareable over the Internet, increasing communication between customers and suppliers (Dieter, 2000), but also because they represent a good trade-off between perception of product representation and frequency of use, in comparison with hand-made sketches, scale models, prototypes, mock-ups, construction design virtual reality and rapid prototyping (Engelbrektsson and Söderman 2004).

The popularity of CAD representation for conveying heterogeneous design information also depends by the problems related to the integration of new information visualization tools in daily engineering work practices (Sedlmair et al., 2011). Experts are often very accustomed to and effective with traditional tools and results, being reluctant to learn a new system (Sedlmair et al., 2011). Also, the integration of a new visualization tool in the existing company software package has often been found challenging (Sedlmair et al., 2011).

Service Explorer (Sakao et al., 2009) is one of the most known examples of CAD-based environment for PSS conceptual design. It includes a view editor, an activity blueprint editor, and a behavior blueprint editor (Hara et al. 2009). Application examples are reported both by Sakao et al. (2009), with regards of the design of pay- 
per-wash service, and by Akasaka (2012), for the design of an accommodation service. Isaksson et al. (2009) provide another example that relates to the use of CAD to enable service visualization in an engineering design environment. The approach is based on the association of rules and dependencies between service phases directly to the CAD model of a component. This work in particular, despite describing an approach not mature enough for a real industrial application, underlines the necessity for the visualization tools to move the focus from the process/stakeholders mapping to a higher level of information detail, in order to better support designers when physically designing an artifact in their day-by-day activity.

\subsection{Color-coding for information visualization in CAD}

In design "Simplicity is Power" (Salustri et al., 2008): the simpler is the tool the easier it is to use and the more likely users are to adopt it willingly and naturally. The use of CAD tools for value visualization is, in this sense, a sound choice: Not only CAD is familiar to designers and engineers, but also creates an immediate link between the value information and the forthcoming product, raising the level of understanding on how a geometry influence value provision.

Although for specific analyses there is still a need to look into tabular data or graphs, the use of CAD representations is a way to bring "value" closer to the PSS hardware. This is supposed to enhance the way individuals understand the system intent, fostering associative processing and enhancing the collaborative decision making process.

A basis question at this stage is: How to make the best use of CAD to foster communication and interaction, to "catch" the attention, to provide an overview, and to welcome queries on value-related matters from the member of a cross-functional team?

The use of color-coded means for value visualization was explored mainly because of the beneficial effects of colors, with regards to associative processing and 
information overload, documented in literature (Severin, 1967) Colors have been found to be the most effective cue for aiding visual searches (Christ, 1975), as also proven experimentally by Smallman and Boynton (1993). Properly used colors improve the usefulness of an information display system (Murch, 1984). Subjects with color-coded reports have been found to obtain a significantly higher average profit over the first 10 trials and complete tasks using fewer trials (Benbasat, 1986). The processing of color information, in fact, does not require large amounts of cognitive capacities (Treisman, 1987) and precedes the processing of other attributes (Karayanidis and Michie, 1997). Furthermore, as the color of objects is stored in long-term memory together with other object information (e.g., Hanna and Remington, 1996), it provides an additional cue for memory retrieval.

By making information more salient, color-coding should provide learners with a better understanding of the structures underlying a domain (Keller et al., 2006), increasing computational efficiency, knowledge acquisition (Dwyer and Moore, 2001) and associative processing (McNab et al., 2009). Keller et al. (2006) conclude that information visualization using a meaningful color-coding is likely superior to those without color-coding, thanks to all these processing advantages and to the use of multiple memory traces.

\section{Development of the Lifecycle Value Representation Approach: finding from the empirical study}

The first step toward the definition of the approach related to the identification of the industrial needs concerning the communication of value related information in preliminary design.

A major ambition for manufacturers is to use value as a transparent and well-understood driver for preliminary product and service development. Since few reliable data about 
new products are available in preliminary design, the stakeholders responsible for the value evaluation of new solutions have to approach the assessment in a qualitative way. The findings of the study describe a set of preferences for representing value information to cross-functional and cross-organizational design teams. Methods and tools for value visualization are requested to:

- Express value contribution using a numerical metric, defined as 'Value Score', to enable comparison between heterogeneous value dimensions.

- Highlight areas that are negatively and positively affected by new designs (compared to a product baseline) to raise awareness of dimensions that necessitate deeper value studies or areas where to trade off excellent performances with others where value contribution is lower.

- Link the value assessment results to the product geometry/shape and to the requirements description, to facilitate the recognition of "patterns of behavior" to expert eyes.

The definition of a value score is often based on assumptions drawn by the personal experiences and background of the people involved in the project. In such a context, the need analysis has highlighted a set of critical aspects to be addressed when approaching value visualization.

- Value needs to be expressed in relative terms, on the basis of well-recognized benchmarks. Absolute figures are characterized by too much uncertainty and are poorly reliable.

- Value dimensions and drivers need to capture the multidimensional nature of value, by extending economical criteria to encompass more intangible aspects 
(e.g., timeliness, comfort, adaptability) and including software and service aspects.

- Value information needs to be more closely related to the requirements description to make easier for engineers to elaborate on value aspects during trade-offs analysis.

- Value information need to be closely related to the 3D product geometry/shape so that the audience does not need to know the specific terminology for each component, thus making it easier to raise question and interest.

Emerging from these needs the process toward value visualization is built on the three activities here listed, and described in detail the following sections:

- Translating the value analysis outcome into value scores

- Mapping value scores to a color scale

- Visualizing the results (presented through an aerospace example)

\subsection{From the value analysis results to relative value scores}

The empirical investigation has shown that value assessment in preliminary design needs to be supported by solid benchmarks to enable more effective decision-making activities, especially when talking about "soft" aspects (such as software and services) that might be difficult to grasp by the engineering teams without a reference example. For instance, taking into consideration the development of an aero-engine, it is relatively easy for an experienced engineer to understand the value of reducing by one kilogram the total weight of a component; however, it is not straightforward to understand the effectiveness of this change in terms of manufacturing commonality with other components or adaptability in different engine configurations. 
More than in producing an absolute value score teams are interested in understanding how a concept is positioned against relevant benchmarks, which is how much a solution is better-or worse - than previous options. The empirical study has shown a clear preference towards establishing two benchmarks: a product baseline (such as the actual product performances) and a target (such as the specification of a vision emerging from long-term forecasts). Furthermore, given the difficulties of obtaining reliable quantitative data about the value drivers, the stakeholders have expressed a preference towards reducing value assessment outcomes to simple scalars. Hence, the outcomes of early value assessment models are mapped against a numerical scale to facilitate trade-off analysis and to enable the benchmarking of value dimensions different in nature. The scale chosen - Design Merit Score Scale (DMSS) - is a 9-point scoring system conceptually derived from the Technology Readiness Level (Mankins, 1995) scale. The DMSS transforms value model results into scalars by applying an algorithm that uses as input the value model results - called Design Merit (DM) by the authors - for a given option $\left(D M_{n}\right)$ for the baseline $\left(D M_{b}\right)$ and for the target $\left(D M_{t}\right)$, and gives as output the concept value score $\left(S_{n}\right)$. The value Score $\left(S_{n}\right)$ for the given option is computed using the formula:

$$
S_{n}=\frac{\left(S_{t}-S_{b}\right)\left(D M_{n}-D M_{b}\right)}{\left(D M_{t}-D M_{b}\right)}+S_{b}
$$

where $\left(S_{b}\right)$ represents the value score for the baseline, which is a-priori set equal to 3, while $\left(S_{t}\right)$ represents the value score of the target, which is a-priori set equal to 8 . It has to be noted that the formula is only applicable when:

$$
\frac{\left(7 D M_{b}-2 D M_{t}\right)}{\left(S_{t}-S_{b}\right)} \leq D M_{n} \leq D M_{t}
$$

On one hand, in case:

$$
D M_{n}>D M_{t}
$$


the algorithm automatically assigns a score of 9 to the design alternative. $S_{n}=9$ denotes a design better in value compared to what was considered as the best desirable outcome for the forthcoming solution.

On the other hand, in case:

$$
D M_{n}<\frac{\left(7 D M_{b}-2 D M_{t}\right)}{\left(S_{t}-S_{b}\right)}
$$

the algorithm automatically assigns a score of $1 . S_{n}=1$ denotes a design scoring significantly below the baseline.

This essentially renders four main areas:

- $\mathrm{Sn}=1 / 2$ indicates NO-GO designs, whose value contribution is below the baseline. Based on the criticality of the value driver, this may cause the design to be definitively killed for not satisfying the minimum threshold set by the baseline. Otherwise, if the criticality is low, engineers may decide to accept a lower value score if this allows for more important dimensions to be improved.

- $\mathrm{Sn}=3 / 4$ indicates designs that meet the minimum threshold. This score might be considered satisfactory if the criticality is low and major improvements have been achieved in dimensions with higher priority. For more critical aspects, it may trigger the decision to kill the development process, especially when resources for rework activities are limited.

- $\mathrm{Sn}=5 / 6 / 7$ indicates designs in the GO area, although attention has to be paid on the reliability of the value assessment results. The design is moving in the right direction, but some refinements may still be made to achieve the desired development process outcome.

- $\mathrm{Sn}=8 / 9$ indicates designs with a higher value than what was originally intended. Engineers can further analyze such over-the-target dimension to trade-off 
excellent capabilities with other drivers that are performing poorly, being free to decrease the value of the first in order to increase the value of the latter.

\subsection{Mapping value scores to a color scale}

Given a feature, a part, or an assembly, a preference has been expressed toward representing the outcome of the value assessment using 3D color-coded representations (i.e., associating each feature, part, or assembly to a color). In the specific area of Computer Aided Design, in fact, color-coded 3D models have been extensively used to display the outcome of heterogeneous types of analysis, such as cost calculation, mechanical and electromechanical simulation, tooling and fixture design and engineering process management. The use of basic colors has not been preferred as experiments have shown that they do not to segregate "exceptionally well" (Smallman and Boynton, 1993) and that for specific applications chromatic gradation within hue or color category may be more appropriate. The color scale selected features different color nuances as shown in Figure 2, ranging from red (lowest value contribution, $S_{n}=1$ ) to green (highest value contribution, $S_{n}=9$ ).

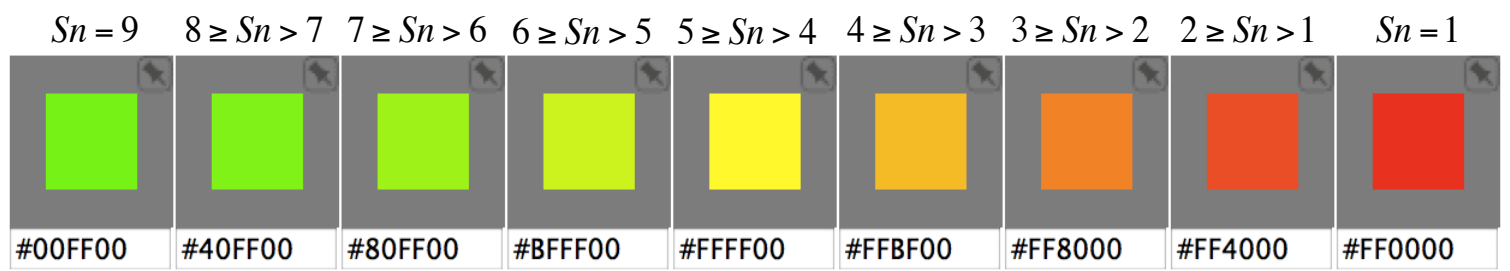

Figure 2: Color scale for value visualization.

Colors are merely the chromatic translation of the value scores expressed at different levels. In theory, there is no limitation to the level of granularity of the color-coded visualization, as far as a relevant system feature has a value score associated to it. To enable the color-coded visualization to span both vertically, representing value with different levels of granularity, and horizontally, along different value dimensions and 
drivers, the underlying value models need to embed weighting mechanisms, able to stress the importance of particular value drivers over others.

Value scores can be then aggregated and balanced, depending on the wishes of the value analysis team, and a color-coded visualization can characterize parts, sub-systems, complex assemblies or whole systems. For instance, a team focusing on the design of a whole aircraft engine, might be interested in visualizing the value performances associated to main sub-systems and components, without going deep into the details of each part (Figure 3a). Another team dealing instead with the design of a aero-engine component, would most likely focus the value analysis on how each part of the component contributes to the achievement of the final design objectives (Figure $3 b$ ).

\subsection{Visualizing the results: LiVReA applied to an aero-engine component}

Once the value scores are mapped to the color scale, colors are displayed by means of 3D CAD models. Scores and colors are translated into CAD model properties in a CAD/PLM environment. This step requires neither advanced computational capabilities nor technological improvements, because the visualization of colored properties in parts or assemblies is a feature currently available in most CAD environments.

An aircraft engine component is here used as an example of visualization. The aerospace industry has been chosen as a reference because it provides one of the main examples of PSS offers, with the "Total Care" package for aircraft engine offered by Rolls Royce (Harrison, 2006). In this context sub-system manufacturers have the ambition to establish a link between the technical parameters and the emerging valuerelated aspects (Collopy and Hollingsworth, 2011). In the aerospace supply chain the ambition is to use value as a transparent and well-understood driver for preliminary 
product and service development (Bertoni et al., 2011), as pointed out by one of our contacts in the aero-engine manufacturing business:

"Nowadays you can easily tell why a solution is the optimal one in terms of performances, however it is not straightforward to see if it is optimal also from a value perspective. Hence, we have to look at people, tools, processes for developing the optimal solution both from a business as well as customer viewpoint”.

Figure 3 shows an example of value visualization in the CAD environment for a particular value dimension ('Logistic' in this case), and considers two levels of detail. The figure serves only as a demonstrative example to clarify the visualization approach, and the possibility of applying it at different levels of detail. Figure 3 a shows the results of a value assessment performed at engine level: The components pictured in red feature a value score lower than the baseline design, for instance because they require more storage space. The components pictured in green feature a value score close to the target for the project, (due, for instance, to better shipping or handling characteristics). The same logic can be applied at a lower level, to display the contribution of a specific engine component, such as the intermediate case (IMC) in Figure $3 \mathrm{~b}$. In this example the IMC hub outer wall, displayed in dark red, shows a deficit in value contribution for the value dimension into consideration, while the outer fan case, displayed in green, positively contributes to the IMC value.

In the end, visualization facilitates the benchmarking of different design alternatives upon selected value dimensions. Thanks to this visualization designers aiming at improving the logistic performances of the new product have a clear insight of which components, or sub-components, are the most critical to work on to target specific aspects of the final product. 


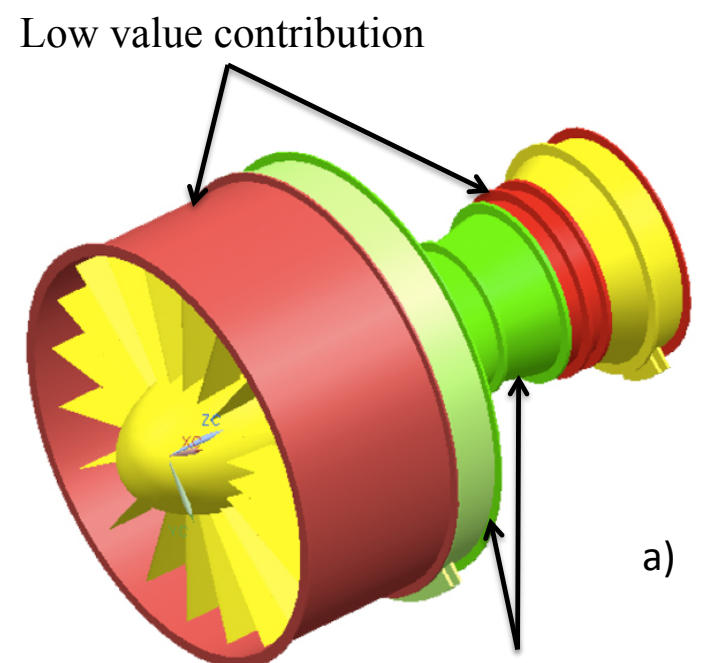

High value contribution

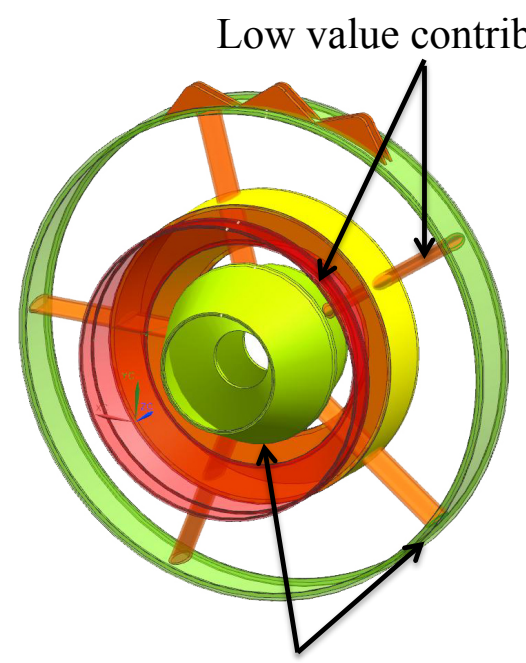

High value contribution

Figure 3. Example of color-coded value visualization at engine level (a) and component level (b).

\section{Preliminary testing of the color-coding approach: methodology and experiment setup}

Laboratory experiments have been conducted to gather factual data about the benefit of using color-coded CAD models for representing the value of PSS design concepts. The testing activities have featured design sessions, analyzed through protocol analysis, whose objective was to measure the effectiveness of color-coded CAD models as value carriers, by comparing them with other forms of visualization, such as QFDlike color-coded tables. The choice of a QFD-like representation as form of comparison was driven by the recognition of QFD being a well-established method largely adopted during the design of subsystems and components integrated in larger systems.

Protocol analysis considers the designer's activity as composed by a sequence of actions, each typically lasting for a few seconds. This makes possible to study the design process by observing the temporal aspect of a design session (Mc Neill et al, 1998) capturing designers' behaviors as a sequence of activities. The coding scheme for the analysis was composed of 26 micro strategies grouped in 4 main categories (Table 1). The scheme is derived from the one proposed by Gero and Mc Neill (1998), which is 
acknowledged as one of the most detailed and successful for the analysis of protocols

(Coley et al., 2007). The three original categories from Gero and Mc Neill (1998) have been expanded with the "Analyzing Problem" category proposed by Mc Neill et al.

(1998). The micro strategies mirror what proposed by Sakao et al. (2011), who

conducted an experiment that, similarly to what done by the authors, relates to the

design of a PSS. Four additional micro strategies were introduced to stress the focus on

value aspects, namely, analyzing previous evaluation, justifying previous evaluation, questioning previous evaluation and justifying proposed solution through previous evaluation.

Table 1. Micro-strategies and categories adopted for protocol analysis

\begin{tabular}{|cc}
\hline Name & Code \\
\hline Analyzing Problem & $\boldsymbol{A}$ \\
Analyzing a Problem & $A P$ \\
Questioning a Problem & $A Q$ \\
Justifying a Problem & $A J$ \\
Agreeing to a Problem & $A A$ \\
Disagreeing to a Problem & $A D$ \\
Evaluating a Problem & $A E$ \\
Analyzing Previous Evaluation & $A A E$ \\
Justifying Previous Evaluation & $A J E$ \\
Questioning Previous Evaluation & $A Q E$ \\
Postponing Analysis of the Problem & $A P A$ \\
Proposing Solution & $\boldsymbol{S}$ \\
Proposing a Solution & $S P$ \\
Clarifying a propose solution & $S C$ \\
Retracting a previous solution & $S R$ \\
Making a Design Decision & $S M$ \\
Consulting External Information & $S C E$ \\
Postponing a Design Action & $S P O$ \\
Looking Ahead & $S L A$ \\
Looking Back & $S L B$ \\
Analyzing Solution & $\boldsymbol{Z}$ \\
\hline Analyzing a Proposed Solution & $Z A$ \\
Justifying a Proposed Solution & $Z J$ \\
Justifying a Proposed Solution through previous & $Z J E$ \\
evaluation & \\
Calculation on a Proposed solution & $Z C$ \\
Postponing an Analysis of Action & $Z P$ \\
Evaluating a Proposed Solution & $Z E$ \\
Explicit Strategies & $\boldsymbol{E}$ \\
Referring to Application Knowledge & $E A K$ \\
Referring to Domain Knowledge & $E D K$ \\
Referring to Design Strategy & $E D S$ \\
\hline
\end{tabular}


Eight experiments, took place between January and February 2012. A pilot session also took place in December 2011 and served the purpose of verifying and adjusting the variables of the study.

The experiment featured a fictional design problem, which considered a barbeque equipment manufacturer aiming to shift its business focus, from selling the equipment through its retail network to renting it to the final users. The participants were asked to redesign grills and accessories to make them more value adding in a situation where they are rented and delivered "just in time" to the customer, with the company taking care of all the service-related aspects, e.g. maintenance, cleaning, delivery.

The design sessions involved 26 students allocated randomly to 8 teams. A set of preliminary information about the previous products of the company was available to all the participants. In particular two design alternatives were described: an "old" solution and an "actual" solution.

To reduce the effect of bias, such as the "feeling of being observed" (Rosenthal, 1966) it was made clear that the design task and the designers would not be evaluated, similarly as what proposed by Ahmed (2007), that is no attempt was made to assess the quality of any design work. The observations were transcribed from the audio and video recordings.

The value assessment reports, distributed to all the teams, were the main source of information for the redesign activity. The reports contained information about the capability of the old and actual design to fulfill the customer value scales. The reports showed a comparison between the old and the actual solution on the basis of a set of value dimensions and value drivers, which translate the expectations and the needs of the stakeholders into quantifiable criteria. Five value dimensions were defined, each of 
them built up by two to five specific value drivers. The value dimensions and the related value drivers are shown in Table 2.

Table 2. List of value dimensions and value drivers for the experiment.

\begin{tabular}{cl}
\hline Value dimensions & Value drivers \\
Operational & Warming speed \\
& Cooling speed \\
& Ergonomics \\
& Heat distribution \\
Service & Safety \\
& Reparability \\
& Cleaning \\
& Mean time between failure \\
& Assembly time \\
& Packaging \\
& Weight \\
& Size \\
& Foldability \\
& Material cost \\
& Manufacturing cost \\
& Assembly cost \\
& Brand Acknowledgment \\
& Environmental impact \\
\hline
\end{tabular}

The value assessment report featured two alternative visualizations (Figure 4). Four teams received the reports in a QFD-like format, i.e. the results of the benchmarking were visualized as numbers from 1 to 9 in the form of printouts of an excel table and each table cell was filled with the corresponding color. The other 4 teams received the value assessment results as printout of color-coded 3D barbeque models. In this case the report did not show any number, but the benchmark information was directly translated to colors in the printout of the barbeque model. During the experiments the teams were not aware of the difference in the reports. 


\begin{tabular}{|l|c|c|}
\multicolumn{3}{|c|}{ Color-coded tables } \\
\hline & Reparability & Cleaning \\
\hline Cover & 7 & 7 \\
\hline Case & 5 & 3 \\
\hline Frame & 2 & 3 \\
\hline Support & 3 & 7 \\
\hline Grill & 4 & 8 \\
\hline Air system & 3 & 3 \\
\hline Gas Cylinder & 4 & 3 \\
\hline
\end{tabular}

Color-coded 3D models
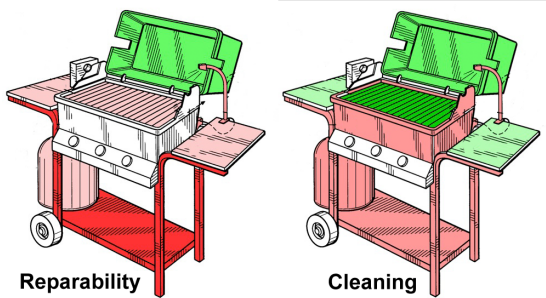

Figure 4. Color-coded tables vs. color-coded 3D models.

All the sessions featured the same schedule. The task was explained during a 20 minutes preparatory meeting. Each team had then 25 minutes to analyze the report and come up with a new design. Additional 15 minutes were given to prototype a solution to be later presented to the other groups.

To provide a wider set of data to be compared with the results of the protocol analysis, the observations were complemented by a questionnaire focusing on the use of the value assessment report.

The content of the sessions were transcribed and codified separately by two encoders. This was done to grant the coding consistency, and the level of agreement between the two coders spans from $65 \%$ to $75 \%$ depending on the experiment analyzed. The final version of the coding was obtained by the comparison of the two protocols and by discussing and agreeing on the non-aligned judgments. 


\section{Results from the experimentation activities}

\subsection{Result at aggregate micro strategy level}

The analysis first focused on the categories of micro strategies (see Table1). Figure 5 displays the average time spent on each category of micro strategy (bold lines) and the standard deviation (thin, dashed line) calculated from the empirical data. A clear trend emerged in terms of time spent on analyzing problem and solutions. The groups using color-coded CAD reports spent on average $8.24 \%$ more of the total time in analyzing the problem, corresponding to a relative increase of $26.38 \%$ of time compared to the group using tables.

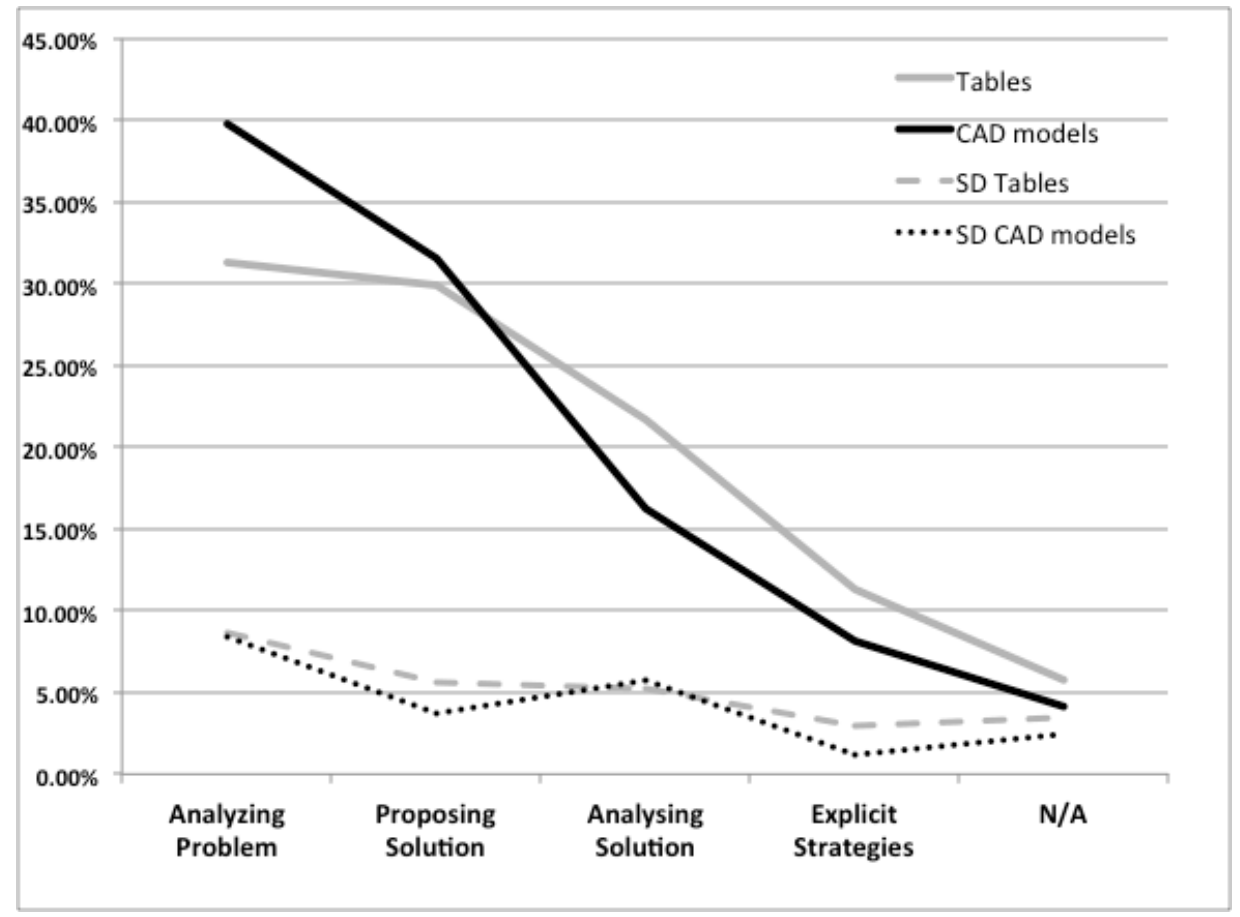

Figure 5: Categories of micro strategies analysis.

Moreover the time spent on proposing solutions slightly increased for CAD models teams ( $+1.81 \%$ on absolute terms, corresponding to $+6.04 \%$ on relative terms). 
By contrast the teams with value reports in tabular format, spent more time in analyzing solutions and referring to explicit strategies. The CAD models team spent $24.46 \%$ less time on analyzing solutions, and $26.83 \%$ less time referring to explicit strategies. It has to be noted that the standard deviation of the average time calculated both for the tables teams and for the CAD teams have only minor differences, and that no particular "out of bound" measurement was found.

\subsection{Results at micro strategy level}

The analysis of the micro strategies has shown which activities were more impacted by the adoption of color-coded CAD model visualization. Figure 6 summarizes the percentage of time spent on only those micro strategies that were discussed for at least the $1 \%$ of the total time of the experiments. All the micro strategies not crossing the $1 \%$ threshold have been considered as not relevant.

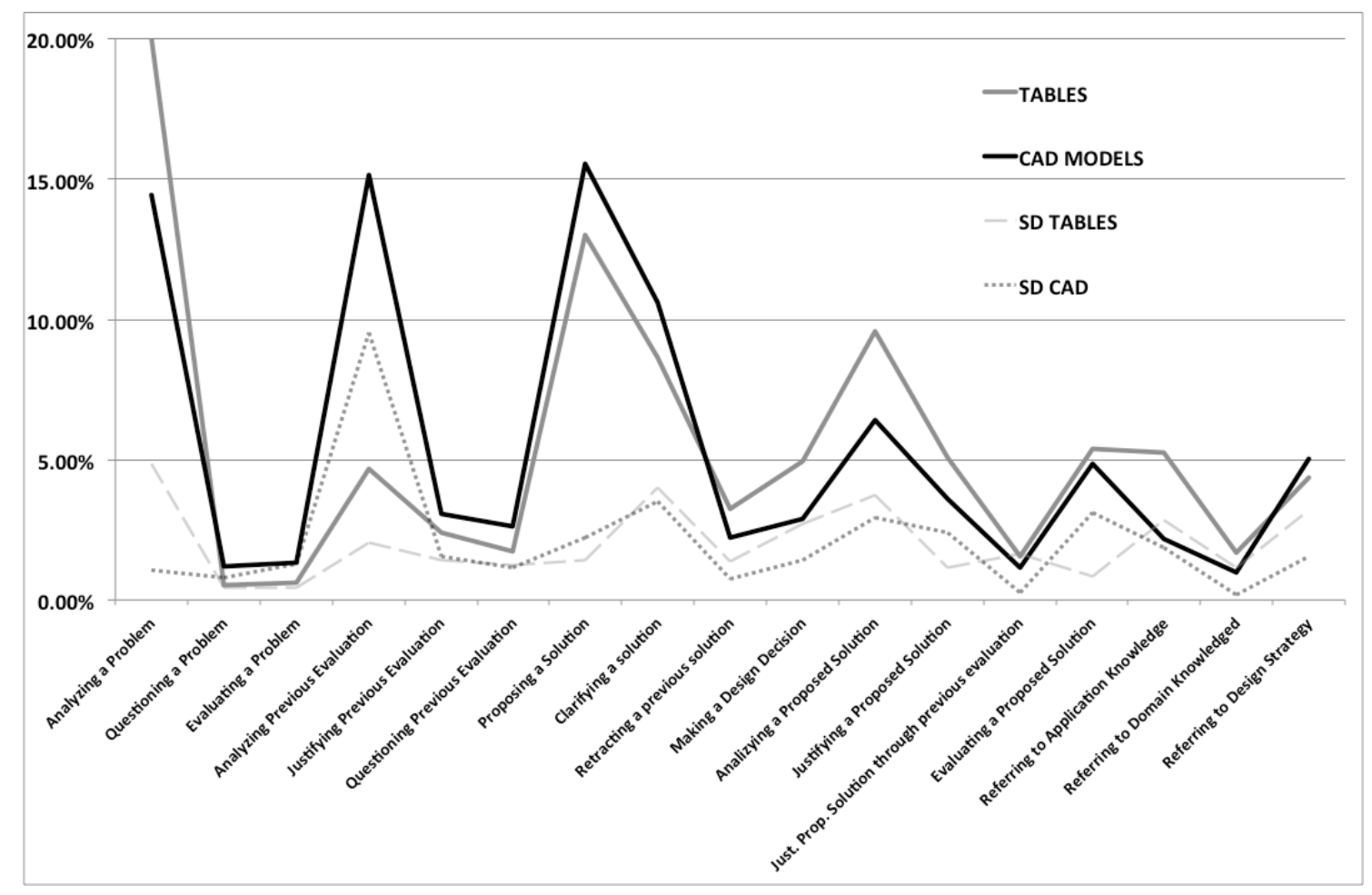

Figure 6: Time spent on micro strategies. 
At a first glance an important aspect to be noticed is the much higher percentage of time spent on analyzing previous evaluation by the teams using color-coded CAD reports. In relative terms they spent $222 \%$ more time in analyzing previous evaluation compared to the team with tabular reports, meaning that, in absolute terms, they spent $10 \%$ more of the total time only on this micro strategy. The same trend can be seen in other micro strategies related to problem analysis, except for the analyzing a problem micro strategy. Grouping the micro strategies referring to the value assessment report, i.e., analyzing/justifying/questioning previous evaluation, and comparing them with the total time spent on problem analysis, a significant change in the design team behavior can be noticed. As shown in Table 3, in fact, the teams using color coded CAD models have dedicated more than half of the time $(53.80 \%)$ spent for problem analysis dealing with the analysis of the value report, while the teams using tabular visualization has spent only the $28.25 \%$ of the time on the same activity.

Table 3. Percentage of problem analysis time spent consulting or discussion value reports

\begin{tabular}{|l|c|c|}
\hline Time spent for: & Tables & CAD \\
\hline Problem analysis & $31.25 \%$ & $39.49 \%$ \\
\hline $\begin{array}{l}\text { Value report analysis } \\
\text { during problem analysis }\end{array}$ & $8.83 \%$ & $21.24 \%$ \\
\hline Ratio & $28.25 \%$ & $53.80 \%$ \\
\hline
\end{tabular}

The analysis of the transcripts has shown that the teams using color-coded CAD models have spent more time in proposing and clarifying solutions. On average $2.73 \%$ more of the total time was spent in proposing a solution, corresponding to a relative increase of $20.98 \%$ compared to the groups using tabular reports. A slightly similar increase is visible for clarifying a solution, which had an increase of $1.97 \%$ in absolute terms and $22.85 \%$ in relative terms.

The groups with color-coded CAD models also show a tendency to propose solutions that are not retracted during the session. This has generate an average 
reduction of the total time spent on this activity of the $1.02 \%$, spending $31.41 \%$ less time compared to the tabular visualization format.

\subsection{Qualitative results}

The last 15 minutes of the experiment were dedicated to fill in an individual questionnaire about the personal feelings and behaviors adopted during the experiment. The questionnaire was run with the aim to check the consistency of the quantitative results obtained through protocol analysis by adding a subject of comparison, to either strengthen or weaken the findings. The first part of the questionnaire featured 8 statements about the effectiveness and the usability of the approach. The participants were asked to state their opinion using a 5-steps scale (strongly agree, agree, uncertain/not applicable/disagree/strongly disagree). The aggregated results of the questionnaires are shown in Figure 7, where 5 means "strongly agree and 1 "strongly disagree".

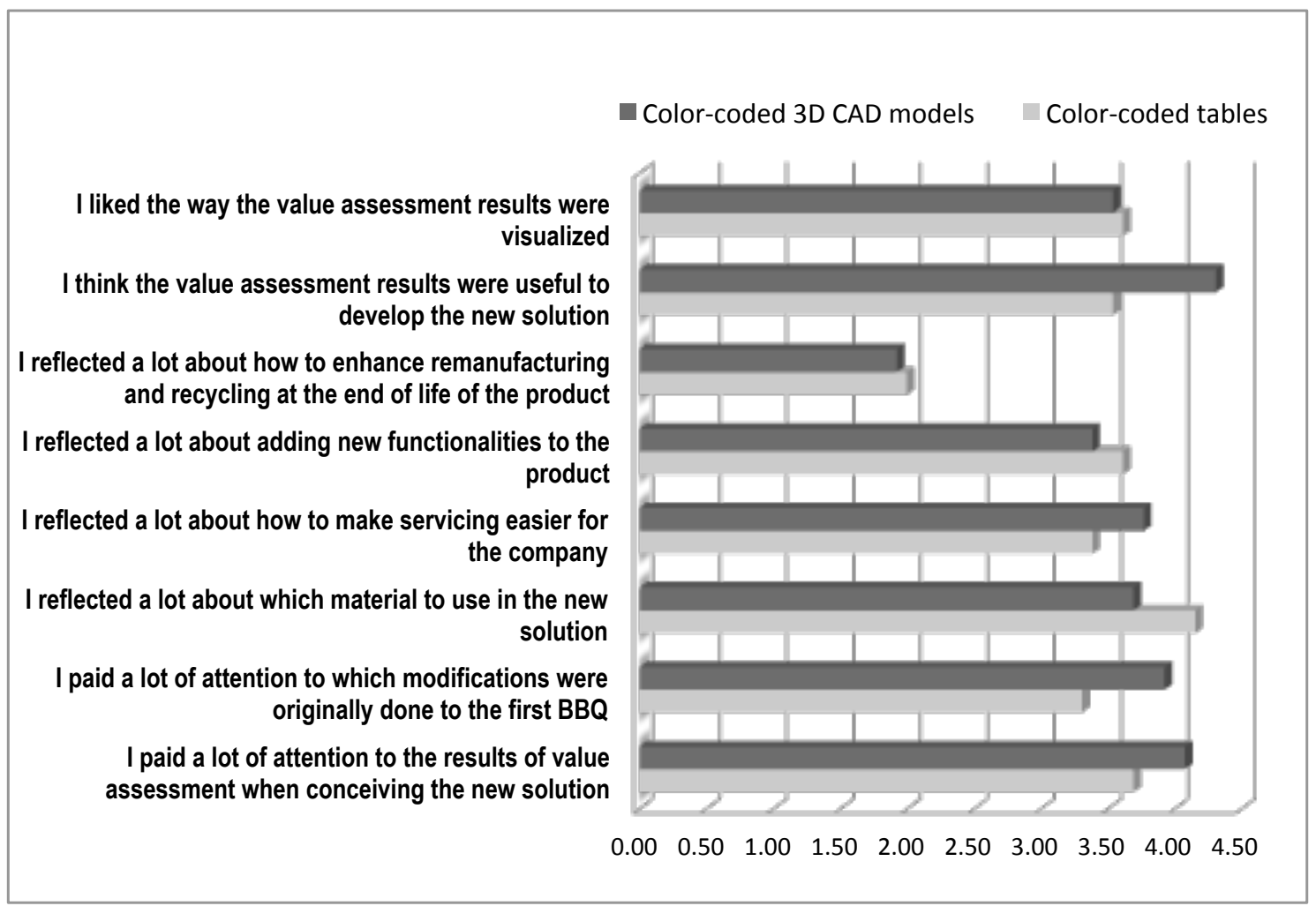

Figure 7. Results of the surveys. 
Because of the limited sample of respondents and of the small range of variation of the answers, the qualitative analysis taken stand-alone cannot be considered as satisfactory to draw generalizable conclusions about the effectiveness of the approach. However, by analyzing the results in the light of the finding from the protocol analysis, the questionnaire seems to confirm the hypothesis that color coded CAD models improve the perception of the value assessment results. CAD models seem also to improve the students' capability of reflecting on service aspects. Furthermore, colorcoded models seem to have improved the designers' capability to reflect on the modifications originally made to the first barbeque, as well as on the value assessment results when thinking about the new solution.

The second part of the questionnaire featured open-ended questions. Overall, colorcoded 3D CAD models received 9 positive feedbacks, while color-coded tables only 5. The use of the 3D CAD models have been acknowledged to facilitate searching for value information and to enhance the processing of the value analysis results under time pressure, while tables have been generally found hard to connect with the physical product.

\section{Discussion}

This section discusses the three main findings of the paper. Firstly, the authors analyze the meaning of value models to guide the early design stages of PSS hardware. The results of these models is what LiVReA eventually displays, hence it must be ensured that they are significant for the designers before discussing the implementation of the visualization approach itself. Then, the focus is shifted on how value visualization is realized, and on the use of 3D CAD models in particular. Eventually, the authors 
discuss the results of the experimental activities, and their significance for the design process.

\subsection{Implications and limitations of value modeling}

The use of value models aims to raise awareness on how a product/technology will impact the performances of a PSS, and therefore its value. By highlighting strengths and weaknesses of alternative hardware concepts - along multiple value-related dimensions reflecting the needs of different types of stakeholders - value model results stimulate early stage discussions about value provision, guiding the choice toward the solution that is best aligned with the overall intent of the design project.

The objective of the paper is neither to analyze in detail how to build value models, nor to compare value-oriented methodologies available in literature. Nevertheless the work creates a first link between the existing contributions in the topic on PSS value visualization and the methodologies and criteria for value analysis in complex systems, mostly discussed in the system engineering (SE) field. Emerging from the empirical study it provides guidelines to enable the definition of a consistent process to build and manage a suitable value model to fit the need for value visualization.

Value Dimensions and Value Drivers are proposed as a bridge between PSS and SE, to guide the assessment of how a technical solution contributes to a complex productservice system. The definition of such dimensions and drivers is the most critical step in the process. They have to be customized for each development, balancing stakeholders' needs and company objectives. On the one hand, they have to be generic enough both to mean "something" from a PSS point of view and to be grasped by stakeholders without technical background. On the other hand, they must be specific enough to be measured, to allow benchmarking alternative concepts with sufficient confidence and detail. Similarly, the design team must set reasonable and understandable references, when 
defining baseline and targets for benchmarking solutions. Value dimensions and drivers provide the necessary input for the visualization, thus they have to be set before the implementation of the visualization approach itself. The underlying value models need to manage their relationship and relative importance dealing with performances and effects that might be contrasting (i.e. the improvement of a value driver might impact positively a value dimension and negatively another).

Value models attempt to quantify a generally subjective and qualitative arena, namely making value based decisions with relatively little information. There is a risk, however, associated with such early phase "quantification" of choices. The use of value models has the potential to effectively devalue the engineering process itself by giving the appearance that engineering (quantitative evaluation) is occurring. Hence, the intrinsic subjectivity and qualitative nature of the process has to be addressed and communicated to correctly support decision-making (Blanco et al., 2007). The authors are currently exploring the use of Knowledge Maturity (see: Johansson et al., 2011) as a way to help decisions makers to understand the level of reliability and fidelity of the knowledge on which the value model is built. A Knowledge Maturity assessment aims at answering questions such as: does the output of the value model reflect assumptions or verified facts? Or, similarly: are there specific knowledge assets that would need further development to clarify the meaning of a value score? By adding a knowledge maturity dimension, decision makers are more informed, mitigating the risk associated with the "quantification" of choices.

It is responsibility of project leaders or managers to decide how many criteria are enough to enable a sound decision, to set the correct references, to sort among trade-offs and to understand how dimensions and drivers should weight in the final choice. A problem observed in the study is that they often are too deep inside their own working 
field to have a complete understanding of the implications of a given technical solution. To cope with this problem previous research has suggested the introduction of a new actor in the process, named Value Analyst (Bertoni et al., 2011). This actor should possesses enough knowledge of the dynamics of the system along its lifecycle, to guide the definition of the value-related criteria, set the boundary conditions for the analysis and prepare the ground for the value assessment task. Although the empirical study showed no clear examples of value analyst in aerospace, the development of such capabilities is believed crucial by the authors to enable the implementation of value assessment processes in real working scenarios.

\subsection{Implications and limitations of value visualization}

The purpose of value assessment is not primarily to have an exact measurement; rather is to have a common denominator that triggers the debate around the team members' perception of value contribution, especially when opinions differ.

By exploiting the benefits of color-coding for information visualization, LiVReA enhances the communication of value information, linking it to the geometry of the hardware to be designed. In this sense LiVReA does not play a role in limiting the amount of information (i.e. its adoption does not reduce or increase the quantity of information to be considered). Rather it aims at communicating information in a more effective way, leveraging associative processing with the use of a color-coding scheme in a CAD environment.

Literature has shown that many product-oriented companies aiming to offer PSS still continue to focus their design activities on hardware and related technical issues (Sundin et al., 2009). Such situation is exacerbated when designers work in long and complex development processes, which feature the integration of several components 
into a complex system, and which are regulated by strict contractual requirements. Radicall innovations, perturbating the established system design and the activities of other actors within the supply chain, are not likely to happen easily. This is particularly true when dealing with products with critical requirements on safety and reliability, such as aircraft engine components. In practice, this means that innovative hardware designs are often variants of an existing technology platform, and are composed by the same basic building blocks. This makes possible to use, early on, a reference geometry for value visualization

LiVReA does not aim at replacing existing methods for PSS representation, rather it complements them, providing a more detailed insight on the technical trade-off associated to the design of PSS, before constraining the solution space with hardwarerelated decisions. Color-coded representations work as a catalyst for discussions around value contribution, facilitating collaboration and explicating gaps in the knowledge base. They function as coordinative artifacts (Schmidt and Simone, 2002) or boundary objects (Star and Griesemer, 1989): by challenging individual's perception of the knowledge base, they help individuals in synthesizing what they know, sharing perceptions and creating new knowledge.

LiVReA provides means to couple technical and value-related information in preliminary design that cross the limits set by the context described in this paper. It can be seen, for instance, as an enabler to the development of more sustainable and environmental friendly solutions: color coding can be used to display the fulfillment of end user, customer, company, society and environmental needs, stressing the importance of later product lifecycle phases in early design. Similarly, the approach can be applied to display the outcomes of LifeCycle Assessment analysis (see: Arena et al. 2013), communicating the environmental impacts associated with all the stages of a 
product's life from-cradle-to-grave (i.e., using raw material extraction, materials processing, manufacture, distribution, use, repair and maintenance, disposal or recycling as dimensions/drivers).

Testing and verification activities have been initially devoted to gathering qualitative feedback from experts and practitioners about the usefulness of the approach. The use of color-coded 3D CAD models was acknowledged by the industrial partners to improve the understanding of value among the members of the crossfunctional design team, raising awareness on value trade-offs in an early stage. Manufacturers can use LiVReA to communicate across the company functions the impact of different design strategies on the overall offer, while component suppliers can show to the system integrators how a new technology or feature is intended to add value to the stakeholders among the entire lifecycle.

Working with color-coding, it is important to keep in mind that many individuals suffer from problems with recognition and understanding of colorful images and videos. Color deficiency problems are relatively common in aging population: approximately $7.40 \%$ of male European descendants, $4.17 \%$ of Asians, and $2.61 \%$ of Africans, have some kind of red-green color vision deficiency (Sharpe et al. 1999). In a color-coded environment these problems can be addressed by running an appropriate re-coloring algorithm. Image re-coloring is a method of altering the color composition of an image in such a way to make it accessible to a color vision impaired audience (Kuhn et al., 2008). Image re-coloring, which preserves the abundance of visual information within the constraints of a limited color range, counts twenty-four algorithms, broken down into four categories (color contrast enhancing; gamut re-mapping; daltonization; conversion to grayscale) (Culp, 2012). Re-coloring algorithms, although not yet 
implemented in the current demonstrator, have been discussed with CAD/PLM developers and are expected to be integral part of the future full-scale prototype.

\subsection{Significance of the experimental results}

Although limited to a laboratory environment, the results of the testing activities indicate that color-coded 3D models enhance the way the design teams manage value related information during preliminary design. The teams with color-coded CAD models are the ones paying more attention to the value assessment results. This may indicate that the 3D models stimulate a more thoughtful analysis of the problem statement and value contribution, as well as of the interrelationships between needs, value and requirements, before moving to the generation of design solutions. Such better awareness is also reflected by the teams' positive attitude towards inventive and creative activities. The more time spent to comprehend the multifaceted aspects of the problem has caused the generation of more ideas, described with more detail. It has also brought the teams to agree earlier on suitable solutions, which has reduced the time spent retracting previous solutions. This can be interpreted as participants being more aware of the problem statement and able to provide constructive feedback. Also, individuals seem to have built on each other ideas more than with tables, elaborating commonly agreed solutions. In the teams using 3D models, new ideas seem to occur as 'extensions' of previous ones, through sketching and modeling where functional aspects play a key role.

Teams with color-coded tables, instead, have been found to use a pattern of trial and error. They showed the tendency to jump to solutions earlier and to spend more time on the analysis of the functional behavior of an option, then retracting and going back to the problem statement and to domain knowledge to formulate a new proposal. 
In spite of the limited set of data, and of the limitations of the method (Cross et al., 1996), the authors believe that the results can be trustworthy, because protocol analysis is a widely known and proven approach, and previous studies have shown the method to be successfully applied also for a really limited number of experiments (e.g., Kan and Gero, 2008; Stempfle and Badke-Schaub, 2002; Chakrabarti et al., 2004).

Although the observation of design teams in a real working scenario would have been preferable, the sample - engineers in the last year of the Master in product development - is considered relevant for the purpose of the study. As stated by Kleinsmann et al. (2012), master students are advanced beginner, which is designers who understand how to design and take situational factors into account. Furthermore, experiments comparing the decision making of industrial managers with students with no experience, but with the same level of education achievement, showed that no significant difference between the two groups was present (Remus, 1986).

The main difference between novices and experts is that the latter pay frequent attention to the reformulation of the problem (Coley et al., 2007), something which is completely ignored by the novices (Brand-Gruwel et al., 2005), who prefer a pattern of trial and error (Ahmed et al., 2003) although using similar working backward strategies (Ho, 2001). This suggests that the results in an industrial contest will likely differ in absolute terms from what observed in the artificial scenario, although in relative terms the difference between the usage of the two approaches might not be particularly evident. In conclusions, the authors believe that student groups are suitable surrogate for decision makers during experiments of this kind, because they recognize well enough the complexity of the design problem, which is part of expert design behavior.

The authors are also aware that the time allocated to complete the task (25 minutes) may have affected the results, emphasizing aspects that would have been less evident in 
a more relaxed experiment. This last option was considered while planning the experimental activities, but it was believed not to be a realistic enough to test the hypothesis. The design team, even in a very early phase, is always coping with time restriction and pressure. Setting rigid time constraints has helped replicating, in a smaller scale, what happens in real life processes.

There are a few drawbacks documented in literature about running verification activities in artificial scenarios (Sedlmair et al., 2011). However, most evaluations for information visualization tools are still conducted in artificial lab settings (Ellis and Dix, 2006). A main advantage of conducting experiments in a laboratory is that the same design task can be repeated several times and recorded. Video and audio recording is often not permitted by industrial companies (an issue stressed by Ahmed, 2007), and this restricts the amount of data to be collected. Nevertheless, despite the objective obstacles given by companies secrecy policy, the testing of the approach in an industrial environment with the analysis of a real PSS design task would provide additional relevant data to study the effectiveness of the approach.

\section{Conclusions}

Emerging from a study in the European aerospace industry, the paper has proposed a Lifecycle Value Representation Approach (LiVReA) to visualize the value of alternative hardware concepts in PSS preliminary design. The paper has first described the challenges in managing value information when dealing with selection of design concepts. Then, it has presented the results from the literature analysis and the empirical studies, which has lead to the definition of the value visualization approach. Eventually, the methodological and technological enablers for value visualization have been presented, and the results from the validation and testing activity have been detailed and 
discussed. The study has revealed the importance of retaining more than just technical requirements while designing hardware with a PSS perspective in mind, that is, context and design intent are equally important to support early stage decision-making activities. Value Dimensions and Value drivers have been proposed as constructs to capture these aspects, bridging the business and engineering domains.

More in detail the study has shown:

- WHY to visualize value: in preliminary design, the objective is not to produce an absolute rank of design alternatives; rather methods and tools are needed to enhance designers' awareness of (and foster dialogue upon) the multifaceted factors and interactions that impact the behavior of the product/service.

- WHAT to visualize: value has to carry all those information concerning context and intent that are necessary to select the best concept in preliminary design. Value should not be limited to the economic aspects: it should also embed those intangible and service- related dimensions that are usually outside the technical horizon of the engineers. Furthermore, value-related information is hardly mature enough to populate quantitative value models, therefore it is more relevant to highlight gaps and no-go areas for further investigation than provide exact figures for "value".

- HOW to visualize value: the results of a value assessment model shall be visualized in a "lightweight" fashion, preferably through a visual representation encompassing a limited but complete set of key parameters. This is motivated by the need of mitigating information overload issues when complementing requirements information. Engineers and technicians prefer representations that seamlessly integrate with the environment they are familiar with, which is in a 
CAD environment. Color-coded CAD 3D models have been found to be an effective means for value visualization.

The LiVReA demonstrator, which implements the above concepts in a commercial CAD/PLM tool, was found to increase the decision makers' awareness of where value is "hidden" in the product. Experimental activities showed that color-coded 3D CAD models stimulate designers to collaboratively analyze the design problem more in deep, reducing rework when solutions are already spelled and partially validated. This effect is important for PSS design: generating a higher level of understanding of the customers' needs and perceived value scales among designers is acknowledged to be critical in an early phase (Alonso-Rasgado et al., 2004; Woodruff, 1997; Morelli, 2003).

From a design process perspective, the early visualization of the value associated to PSS hardware generates the following benefits:

- Cost could be reduced by preventing late changes due to non-value adding solution strategies that "consume" time and resources,

- Lead-time could be reduced by identifying and instantiating the optimal direction for the development in an early phase of the project,

- Rework caused by the late discovery of the impact of an innovative technical concept at system level could be reduced as well.

The visualization approach is currently under implementation, with the support of a major CAD/PLM software vendor. The opportunity of further integrating the value assessment capabilities in a wider range of commercial software is under study. The results described in the paper will further be validated by means of new experiments, which will focus on the usefulness of the visualization approach in real company 
environment. Eventually, future researches will investigate how to visualize the reliability and the rationale that has lead to the definition of a value score, as well as how to enhance enterprise collaboration capabilities to enable a conjunct management of requirements and value information in the extended enterprise.

\section{Acknowledgements}

The work presented in this paper was performed in the framework of Work Package 2.2 of the European Community's Seventh Framework Programme (FP7/2007-2013) (www.crescendo-fp7.eu) under grant agreement n॰234344.

\section{References}

Ahmed, S. 2007. Empirical research in engineering practice. Journal of Design Research, 6 (3), 359-380.

Ahmed, S.,Wallace, K.M. and Blessing, L.T.M., 2003. Understanding the differences between how novice and experienced designers approach design tasks. Research in Engineering Design, 14, 1-11.

Akasaka, F., Nemoto, Y., Kimita, K. and Shimomura, Y., 2012. Development of a knowledge-based design support system for Product-Service Systems. Computers in Industry, 63 (4) 309-318.

Alonso-Rasgado, T., Thompson, G. and Elfström, B.O., 2004. The design of functional (total care) products. Journal of Engineering Design, 16 (6), 515-540.

Andreasen, M.M., Olesen, J., 1990.The concept of dispositions. Journal of Engineering Design, 1 (1), 17-36.

Arena, M., Azzone, G. and Conte, A., 2013. A streamlined LCA framework to support early decision making in vehicle development. Journal of Cleaner Production $41,105-113$

Aurich, J.C., Fuchs, C. and Wagenknecht, C. 2006. Life cycle oriented design of technical Product-Service Systems, Journal of Cleaner Production, 14 (17), 1480-1494. 
Avison, D.E., Lau, F., Myers, M.D., Nielsen, P.A., 1999. Action research.

Communication of ACM, 42(1), pp. 94-97.

Baines, T.S., Lightfoot, H.W., Evans, S., Neely, A., Greenough, R., Peppard, J., Roy, R., Shehab, E., Braganza, A., Tiwari, A., Alcock, J.R., Angus, J.P., Bastl, M., Cousens, A., Irving, P., Johnson, M., Kingston, J., Locket, H., Martinez, V., Michele, P., Tranfield, D., Walton, I.M. and Wilson, H., 2007. State-of-the-Art in Product-Service Systems. Journal of Engineering Manufacture, 221(B), 15431552.

Becker, J., Beverungen, D.F., and Knackstedt, R., 2010. The challenge of conceptual modeling for product-service systems: status-quo and perspectives for reference models and modeling languages. Information Systems and E-Business Management, 8 (1), 33-66.

Benbasat, B., 1986. An experimental program investigating colour-enhanced and graphical information presentation: an integration of the findings. Communications of the ACM archive, 29 (11), $1094-1105$.

Bertoni, M., Bertoni, A. and Johansson, C., 2011. Towards Assessing the Value of Aerospace Components: A Conceptual Scenario. In: Proceedings of the 18th International Conference on Engineering Design (ICED11), 9, 226-235.

Blanco, E., Grebici, K. and Rieu, D., 2007. A unified framework to manage information maturity in design process. International Journal of Product Development, 4(3), $255-279$.

Borg, J. C., Yan, X-T. and Juster N.P., 2000. Exploring decisions' influence on life-cycle performance to aid "design for Multi-X". Artificial Intelligence for Engineering Design, Analysis and Manufacturing, 14(2), 91-113

Boughnim, N. and Yannou, B., 2005. Using blueprinting method for developing product- service systems. International Conference on Engineering Design ICED 05, Melbourne

Brandstötter, M., Haberl, M., Knoth, R., Kopacek, B., and Kopacek, P., 2003. IT on demand-towards an environmental conscious service system for Vienna. In: Proceedings of EcoDesign'03: Third International Symposium on Environmentally Conscious Design and inverse Manufacturing. Japan, 799-802.

Brand-Gruwel, S., Wopereis, I. and Vermetten, Y., 2005. Information problem solving by experts and novices: analysis of a complex cognitive skill. Computers in Human Behavior, 21 (3), 487-508. 
Bresciani, S., and Eppler, M.J., 2009. The Benefits of Synchronous Collaborative Information Visualization: Evidence from an Experimental Evaluation. Visualization and Computer Graphics, 15 (6), 1073-1080.

Card, S.K., Mackinlay, J.D., and Schneiderman, B., 1999. Readings in Information Visualization; Using Vision to think. Morgan Kaufmann, Los Altos.

Castagne, S., Curran, R., and Collopy, P., 2009, Implementation of Value-Driven Optimisation for the Design of Aircraft Fuselage Panels. International Journal of Production Economics, 117, 381-388.

Cavalieri, S., Pezzotta, G., 2012. Product-Service Systems Engineering: State of the art and research challenges. Computers in Industry, 63, 278-288.

Chakrabarti, A., Morgenstern, S. and Knaa, H., 2004. Identification and application of requirements and their impact on the design process: a protocol study. Research in Engineering Design, 15 (1), 22-38.

Cheung, J., 2012. Application of value-driven design to commercial aero-engine systems. AIAA Journal of Aircraft, 49(3): 688-702.

Christ, R.E., 1975. Review and analysis of colour-coding research for visual displays. Human Factors, 17 (6), 542-570.

Coley, F., Houseman, O. and Roy, R., 2007. An introduction to capturing and understanding the cognitive behavior of design engineers. Journal of Engineering Design, 18 (4), 311-325.

Collopy, P.D. and Hollingsworth, P.M., 2011. Value-Driven Design. Journal of Aircraft, 48 (3), 749-759.

Cross, N., Christiaans, H., and Dorst, K., 1996. Analysing Design Activity, Wiley.

Culp, G.M., 2012. Increasing Accessibility for Map Readers with Acquired and inherited Colour Vision Deficiencies: A Re-Colouring Algorithm for Maps. The Cartographic Journal, 49(4), 302-311.

Dieter, G.E., 2000. Engineering design: a materials and processing approach. Boston: McGraw-Hill.

Duffy, A.H.B., Andreasen, M. M., MacCallum, K. J. and Reijers, N. L., 1993. Design coordination for concurrent engineering. Journal of Engineering Design, 4(4), pp. 251-265.

Dull, R.B., Tegarden, D.P., 1999. A comparison of three visual representations of complex multidimensional accounting information. Journal of Information Systems, 13(2), pp. 117-131. 
Dwyer, F.M, and Moore, D.M., 2001. Effect of color coding on visually oriented tests with students of different cognitive styles. The Journal of Psychology, 125 (6), $677-680$.

Ellis, G. and Dix, A., 2006. An explorative analysis of user evaluation studies in information visualization. Proceedings of the 2006 AVI workshop on BEyond time and errors: novel evaluation methods for information visualization, Venice, Italy, 1-7.

Endsley, R., 1995. Toward a theory of situation awareness in dynamic systems. Human Factors, 37 (1), 32-64.

Engelbrektsson, P. and Söderman, M. 2004. The use and perception of methods and product representations in product development: A survey of Swedish industry. Journal of Engineering Design, 15 (2), 141-154.

Eppler, M.J., 2004. Facilitating Knowledge Communication through Joint Interactive Visualization. Journal of Universal Computer Science, 10 (6), 683-690.

Ericson, Å., Bergström, M., Johansson, C. and Larsson, T., 2007. On the way to knowledge awareness in early design. CIRP 2007, Design Seminar on "The Future of Product Development", Berlin, Germany.

Ericsson, K.A. and Simon, H.A., 1993. Protocol Analysis Verbal Reports as Data. Cambridge, MA: MIT Press.

Geng, X. and Chu, X., 2011. A new PSS conceptual design approach driven by user task model. In: Hesselbach, J. and Herrmann C., eds. Functional thinking for value creation, Springer 123-128.

Gero, S. and Mc Neill T., 1998. An approach to the analysis of design protocols. Design Studies, 19, 21-61.

Geum, Y., Lee, S., Kang, D. and Park, Y, 2011. Technology roadmapping for technology-based product-service integration: A case study. Journal of Engineering and Technology Management, 28 (3), 128-146.

Geum, Y., Park, Y., 2011. Designing the sustainable product-service integration: a product-service blueprint approach. Journal of Cleaner Production, 19 (14), 1601-1614.

Goedkoop, M., van Halen, C.J.G., te Riele, H.R.M. and Rommens, P.J.M., 1999. Product Service-Systems, ecological and economic basics. the Hague: PricewaterhouseCoopers. 
Grönroos, C., 1996. Relationship marketing: strategic and tactical implications. Management Decision, 34 (3), 5-14.

Hanna, A., and Remington, R., 1996. The representation of color and form in long-term memory. Memory and Cognition, 24 (3), 322-330.

Hannah, R., Joshi, S. and Summers, J.D., 2012. A user study of interpretability of engineering design representations. Journal of Engineering Design, 23 (6), 443468.

Hara, T., Arai, T. and Shimomura, Y., 2009. A CAD system for service innovation: integrated representation of function, service activity, and product behavior. Journal of Engineering Design, 20 (4), 367-388.

Harrison, A., 2006. Design for service - Harmonising product design with a services strategy. Proceedings of the ASME Turbo Expo 2006, 2, Barcelona, 135-143.

Ho, C.H., 2001. Some phenomena of problem decomposition strategy for design thinking: differences between novices and experts. Design Studies, 22, 27-45.

Isaksson, O., Larsson, T., and Rönnbäck, A.Ö., 2009. Development of product-service systems: challenges and opportunities for the manufacturing firm. Journal of Engineering Design, 20 (4), 329-348.

Isaksson, O., Larsson, T., Kokkolaras, M. and Bertoni M., 2012. Simulation driven design for product-service systems. In: Shimomura, Y. and Kimita, K., eds.The Philosopher's Stone for Sustainability, Springer, Berlin, 465-470.

Johansson, C, Hicks, B, Larsson, A. and Bertoni, M., 2011. Knowledge maturity as a means to support decision making during product-service systems development projects in the aerospace sector. Project Management Journal, 42 (2), 32-50.

Kan, J.W.T. and Gero, J.S., 2008. Acquiring information from linkography in protocol studies of designing. Design Studies, 29 (4), 315-337.

Kang, C., Hong, Y., Kim, K. and Park, K., 2011. A relation-based model for analyzing ecosystems of products, services and stakeholders. Journal of the Korean Institute of Industrial Engineers, 37 (1), 41-54.

Karayanidis, F., and Michie, P.T., 1997. Evidence of visual processing negativity with attention to orientation and colour in central space. Electroencephalography and Clinical Neurophysiology, 103 (2), 282-297.

Keller, T., Gerjets, P., Scheiter, K. and Garsoffky, B., 2006. Information visualizations for knowledge acquisition: The impact of dimensionality and color-coding. Computers in Human Behavior, 22, 43-65. 
Kim, B. and Lee, K., 2009. Service triangle model: method for developing and representing service experience. In: Service Design Conference 2009, Funchal, Madeira, Portugal.

Kim, Y.S., Wang, E., Lee, S.W and Cho, Y.C., 2009. A Product-Service System Representation and Its Application in a Concept Design Scenario. Proceedings of the 1st CIRP Industrial Product-Service Systems (IPS ${ }^{2}$ ) Conference, 32-36.

Kindström, D., Kowalkowski, C. and Nordin, F., 2012. Visualizing the value of servicebased offerings: empirical findings from the manufacturing industry. Journal of Business \& Industrial Marketing, 27 (7), 538 - 546.

Klein, G.A., 1989. Strategies of decision making. Military Review, 56-64.

Kleinsmann, M., Deken, F., Dong, A. and Lauchec, K., 2012. Development of design collaboration skills. Journal of Engineering Design, 3 (7), 485-506

Kowalkowski, C. and Kindström, D., 2009. Value Visualization Strategies for PSS Development. In: Sakao, T., Lindahl, M., eds. Introduction to Product/ServiceSystem Design, Springer London, London, 159-181.

Kuhn, G.R., Oliveira, M.M. and Fernandes, L.A.F., 2008. An Efficient NaturalnessPreserving Image-Recoloring Method for Dichromats. IEEE transactions on visualization and computer graphics, 14(6), 1747-1754.

Lee, S. and Kim, Y., 2010. A product-service systems design method integrating service function and service activity and case studies. In: Hesselbach, J. and Herrmann C., eds. Functional thinking for value creation, Springer, 275-282.

Lim, C.H., Kim, K.J., Hong, Y.S. and Park, K., 2012. PSS Board: a structured tool for product-service system process visualization, Journal of Cleaner Production, 37, $42-53$.

Ma, Q., Tseng, M.M. and Yen, B., 2002. A Generic Model and Design Representation Technique of ServiceProducts. Technovation, 22, 15-39.

Mankins, J, 1995. Technology Readiness Levels. Advanced Concepts Office, Office of Space Access and Technology, NASA.

Manzini, E., Vezzoli, C. and Clark, G., 2001. Product Service Systems: Using an Existing Concept as a New Approach to Sustainability. Journal of Design Research, 1(20).

Maussang, N., Zwolinski, P. and Brissaud, D., 2009. Product-service system design methodology: from the PSS architecture design to the products specifications. Journal of Engineering Design, 20 (4), 349-366. 
McNab, A.L., Hess, T.J., and Valacich, J.S., 2009. Designing Interfaces for Faster Information Processing: Examination of the Effectiveness of Using Multiple Information Cues. Proceedings of AMCIS 2009, Paper 699.

Mc Neill, T. Gero, J.S. and Warren, J., 1998. Understanding conceptual electronic design using protocol analysis. Research in Engineering Design, 10(3), 129-140.

McNiff, J., 2002. Action research for professional development: Concise advice for new action researchers (3rd ed.). available from: http://www.jeanmcniff.com/ booklet1.html

Meier, H., Roy, R. and Seliger, G., 2010. Industrial Product-Service Systems-IPS2. CIRP Annals - Manufacturing Technology, 59 (2), 607-627.

Mont, O.K., 2002. Clarifying the concept of product-service system. Journal of Cleaner Production, 10 (3). 237-245.

Molloy, E., Siemieniuch, C., and Sinclair, M. 2009. Decision-making systems and the product-to-service shift. Journal of Manufacturing Technology Management, 20 (5), 606-625.

Morelli, N., 2003. Product-Service Systems: a Perspective Shift for Designers. A Case Study: the Design of a Telecentre. Design Studies, 24(1), pp. 73-99.

Morelli, N., 2006. Developing new product service systems (PSS): methodologies and operational tools. Journal of Cleaner Production, 14 (17),1495-1501.

Müller, P., Kebir, N., Stark, R. and Blessing, L., 2009. PSS Layer Method - Application to Microenergy Systems. In: Sakao T. and Lindahl M., eds. Introduction to Product/Service-System Design. London: Springer London, 3-30.

Murch, G.M., 1984. Physiological principles for the effective use of colour. IEEE Computer Graphics and Applications, 4 (11), 49-54.

Novak, J., 2007. Helping Knowledge Cross Boundaries: Using Knowledge Visualization to Support Cross-Community Sensemaking. Proceedings of the 40th Hawaii International Conference on System Sciences, Big Island, HI.

Ntuen, C.A., Park, E.H., and Gwang-Myung, K., 2010. Designing an information visualization tool for sensemaking. International Journal of Human-Computer Interaction, 26(2-3), 189-205.

Remus, W., 1986. Graduate students as surrogates for managers in experiments on business decision making, Journal of Business Research, 14 (1), 1986, 19-25.

Rosenthal, R., 1966. Experimenter Effects in Behavioural Research. New York: Appleton Century Crofts. 
Ross, A.M., Hastings, D.E. and Warmkessel, J.M., 2004. Multi-Attribute Tradespace Exploration as Front End for Effective Space System Design. Journal of Spacecraft and Rockets, 41 (1), 20-28.

Sakao, T., Paulsson, S. and Mizuyama, H., 2011. Inside a pss design process: insights through protocol analysis. Proceedings of the 18th International Conference on Engineering Design, 365-376.

Sakao, T. and Shimomura, Y., 2007. Service engineering: a novel engineering discipline for producers to increase value combining service and product. Journal of Cleaner Production, 15 (6), 590-604.

Sakao, T., Shimomura, T., Sundin, E. and Cornstock, M., 2009. Modeling design objects in CAD system for service/product engineering. Computer-Aided Design, 41 (3), 197-213

Saleh, J.H., Lamassoure, E.S. and Hastings, D.E., 2003. Flexibility and the Value of On-Orbit Servicing: New Customer-Centric Perspective. Journal of Spacecraft and Rockets, 40 (2), 279-291.

Salustri, F.A., Eng, N.L. and Weerasinghe, J.S., 2008. Visualizing Information in the Early Stages of Engineering Design. Computer-Aided Design \& Applications, 5 (1-4), 1-18.

Schmidt, K., and Simone, C., 1996. Coordination mechanisms: Towards a conceptual foundation of CSCW systems design. Computer Supported Cooperative Work (CSCW), 5(2) 155-200.

Sedlmair, M., Isenberg, P., Baur, D. and Butz, A., 2011. Information visualization evaluation in large companies: Challenges, experiences and recommendations. Information Visualization, 10(3), 248-266.

Severin, W., 1967. Another look at cue summation. Educational Technology Research and Development, 15 (3), 233-245.

Sharpe, L.T., Stockman, A., Jägle, H. and Nathans, J., 1999. Opsin genes, cone photopigments, color vision, and color blindness Color Vision: From Genes to Perception. In: Gegenfurtner, K.R., Sharpe, L.T. eds. Color vision: From genes to perception. Cambridge University Press, 3-51.

Shimomura, Y., Hara, T. and Arai, T., 2009. A unified representation scheme for effective PSS development. CIRP Annals - Manufacturing Technology, 58 (1), 379-382. 
Shostack, G.L., 1981. How to design a service. European Journal of Marketing, 16, 4963.

Simon, H.A., 1996. The Science of the Artificial. MIT Press, Boston.

Smallman, H.S. and Boynton, R.M., 1993. On the usefulness of basic color-coding in information display. Displayes, 14 (3), 158-165.

Stacey, M., and Eckert, C., 2003. Against ambiguity. Computer Supported Cooperative Work, 12, 153-183.

Star, S. L. and Griesemer, J. R., 1989. Institutional ecology, 'translations' and boundary objects: Amateurs and professionals in Berkeley's Museum of Vertebrate Zoology, 1907-39. Social Studies of Science, 19, 387-420.

Steiner, F. and Harmor, R., 2009. The Impact of Intangible Value on the Design and Marketing of New Products and Services: An Exploratory Approach. Proceedings of PICMET 2009, Portland, Oregon USA, 2066-2079.

Stempfle, J. and Badke-Schaub, P., 2002. Thinking in design teams - an analysis of team communication. Design Studies, 23 (5), 473-496.

Sundin, E., Lindahl, M. and Ijomah, W., 2009. Product design for product/service systems: Design experiences from Swedish industry. Journal of Manufacturing Technology Management, 20 (5), 723-753.

Treisman, A., 1987. Properties, parts, and objects. In: Boff, K. R., Kaufman, L. and Thomas, F. P. eds. Handbook of perception and human performance. Oxford: Clarendon.

Tukker, A., 2004. Eight types of product-service system: eight ways to sustainability? Experiences from SusProNet. Business Strategy and the Environment, 13(4), 246-260.

Tukker, A. and Tischner, U., 2006. New business for old Europe: product service development, competitiveness and sustainability, Greenleaf Publishing, Sheffield, UK.

Ullman, D.G., 2003. The mechanical design process. New York: McGraw-Hill.

Van Halen, C., Vezzoli, C. and Wimmer, R., 2005. Methodology for Product Service System Innovation: How to Develop Clean, Clever and Competitive Strategies in Companies. Van Gorcum.

Van Someren, M.W., Bardard Y.F., and Sandberh, J.A.C., 1994. The Think Aloud Method: A Practical Guide to Modelling Cognitive Processes. London: Academic Press. 
Vasantha, G.V.A., Roy, R., Lelah, A. and Brissaud D., 2012. A review of productservice systems design methodologies. Journal of Engineering Design, 23(9), 635-659.

Wang, P.P., Ming, X.G., Li, D., Kong, F.B., Wang, L. and Wu, Z.Y., 2011. Status review and research strategies on product-service systems. International Journal of Production Research, 49(22), 6863-6883.

Wenger, E., 1998. Communities of Practice: Learning as a Social System. Systems Thinker.

Woodruff, R., 1997. Customer value: The next source for competitive advantage. Journal of the Academy of Marketing Science, 25(2), 139-153. 